\title{
IRMÃ DE ÍNDIO, MULHER DE BRANCO: PERSPECTIVAS FEMININAS NO ALTO RIO NEGRO*
}

Cristiane Lasmar

Tendo como tema de fundo a dinâmica das relações de gênero no alto rio Negro, o objetivo deste artigo é analisar as transformações que ocorrem na experiência social das mulheres indígenas quando estas se mudam de suas comunidades ribeirinhas para a cidade de São Gabriel da Cachoeira, principal pólo urbano da região. A análise privilegia a perspectiva daquelas pertencentes a grupos da família lingüística tukano oriental, os quais tradicionalmente habitam a bacia do rio Uaupés, afluente do rio Negro em seu curso alto.

Conforme podemos deduzir das descrições etnológicas sobre os grupos do rio Uaupés, a distinção de gênero apresenta ali um rendimento sociocosmológico mais importante do que se percebe em outras regiões etnográficas das terras baixas da América do Sul, onde ela parece subsumida por outras distinções categoriais mais centrais (Descola 2001, Fisher 2001). Com efeito, a temática da separação dos espaços e das atividades cotidianas ou rituais por sexo tem sido objeto de atenção desde os relatos mais antigos sobre os grupos do rio Uaupés, começando a receber tratamento sistemático com a publicação das etnografias modernas (p.ex., Goldman 1963 e 2004, S. Hugh-Jones 1979, C. Hugh-Jones 1979, Jackson 1983, Chernela 1993). De uma maneira ou de outra, todos os autores notam a grande produtividade da distinção de gênero nas concepções indígenas sobre os princípios que organizam a comunidade, a vida social e o cosmos. Além disso, esses trabalhos sugerem-nos que haveria capacidades e modos de poder e agência especificamente masculinos e femininos. Por exemplo, em um livro recente sobre o pensamento dos Cubeo, Irving Goldman salienta a conexão entre gênero e formas distintas de poder, e afirma que "um gênero se diferencia do outro em razão de seu enraizamento em esferas distintas [each gender differs from the other by its rootness in a different sphere] (Goldman 2004:391).

Um ponto a ser destacado é que nessa sociocosmologia extremamente sensível à diferença de gênero, o masculino e o feminino não se equivalem 
em termos de valor, e as relações entre os sexos atualizam-se de modo assimétrico. Isso se exprime, por um lado, nas concepções sobre a origem do mundo e da humanidade (Goldman 2004:384-87); por outro, em alguns aspectos cruciais da organização social. Sendo patrilinear o princípio de descendência e virilocal a regra de residência, o destino das mulheres solteiras é sempre deixar o grupo ao qual pertencem por nascimento; quando casadas, elas são estrangeiras na comunidade em que passam a viver. Os homens, por sua vez, permanecem a vida inteira em sua comunidade de origem, à qual se vêem fortemente associados. Eles detêm prerrogativas que os tornam capazes de recriar ritualmente a ordem mítica e agenciar simbolicamente $o$ processo de reprodução social a cada geração: guardam o conhecimento dos bens esotéricos do grupo, como a mitologia da origem e as rezas xamânicas e possuem direitos exclusivos de acesso aos objetos utilizados durante as cerimônias em que se celebra a conexão vertical entre o grupo de agnatos e seus ancestrais. Tais privilégios ancoram-se na suposição de que existe maior proximidade dos homens com o mundo dos ancestrais - fonte de vida e regeneração espiritual (S. Hugh-Jones 1977:214). Os rituais de iniciação masculina, nos quais ocorrem performances musicais com flautas proibidas às mulheres, constituem o principal contexto de afirmação e atualização do vínculo com o plano mítico-sagrado. ${ }^{1}$

Em trabalhos anteriores, sugeri que um dos sentidos dos rituais das flautas é marcar a exterioridade das mulheres que residem na comunidade, reafirmando sua alteridade e a dos grupos aos quais elas pertencem ou aos quais se unirão por ocasião do casamento (Lasmar 2002, 2005). Isso explica por que, em certos momentos cruciais, elas devem se manter afastadas e invisíveis para quem se encontra no centro da cena litúrgica, sendo a alternância entre momentos de ausência e de presença feminina um dos princípios estruturantes da cerimônia. Num registro sociológico, portanto, pode-se dizer que a marcação da exterioridade feminina representa a outra face da afirmação da identidade do conjunto agnático perante os grupos afins. A meu ver, esse ponto é fundamental, na medida em que esclarece a dialética da identificação e da diferenciação que percorre toda a atividade ritual no alto rio Negro e aparece objetivada na oposição homens/ mulheres.

Entretanto, cabe ainda uma segunda interpretação. Em sua análise sobre os processos espaciais e temporais implicados na produção e reprodução da comunidade barasana, C. Hugh-Jones (1979) apontou a diferença entre dois aspectos da continuidade social no Uaupés: de um lado, os processos relacionados à criatividade masculina — direta, linear, espiritual — de outro, aqueles relacionados à criatividade feminina - indireta, cíclica, material. Assim, a oscilação entre momentos de presença e ausência das mulheres durante o ritual 
das flautas poderia ser entendida como metáfora da própria fisiologia feminina e também do modo específico de contribuição das mulheres à reprodução das comunidades em que vivem. Voltaremos a esse ponto adiante.

Aquilo que estou chamando de uma maior capacidade de "agência espiritual" masculina, e que Goldman definiu em termos de uma "precedência" ou "prioridade" (Goldman 2004:385), se desdobra sobre o terreno das relações cosmopolíticas. Os homens são os legítimos representantes de uma comunidade, tanto no que se refere às relações político-rituais internas e verticais quanto no que tange às relações horizontais com os outros grupos e com os brancos. ${ }^{2}$ Em ambos os contextos, as mulheres ocupam uma posição ambígua, descentrada. As capacidades de agência das mulheres, em contraste com as dos homens, incidem sobre os domínios mais informais da vida cotidiana, nos quais se dá o processo de produção e reprodução dos corpos humanos. Além do domínio da reprodução fisiológica, podemos destacar o da produção de alimentos, da roça e da culinária - trabalhos concebidos como essencialmente femininos.

A associação de homens e mulheres a espaços sociais distintos explicita-se quando comparamos o ritual de iniciação dos rapazes com o das moças. Ao contrário dos rituais de iniciação masculina, cuja ênfase recai sobre a conexão vertical com o mundo dos ancestrais e a diferenciação em relação aos outros grupos, os rituais de iniciação feminina, por ocasião da menarca, abordam e retratam a íntima associação entre o trabalho produtivo e a condição materna. ${ }^{3}$ Além de tema ritual, o nexo simbólico entre a identidade feminina, a capacidade reprodutiva e o trabalho na roça também é evidenciado na mitologia dos grupos do rio Uaupés. A narrativa do roubo das flautas sagradas, por exemplo, reporta-se a uma ocasião em que as mulheres se apoderaram desses instrumentos, passando elas próprias a manejá-los ritualmente. Enquanto as mulheres possuíram as flautas, os homens, diz o mito, "viraram mulheres". Durante um período, eles menstruaram e cultivaram mandioca, até que a ordem das coisas foi novamente estabelecida por uma outra série de eventos (S. Hugh-Jones 1979:127).

A generização de dois modos distintos e assimetricamente dispostos de poder e agência parece ter implicações importantes na forma como os dois sexos percebem os seus respectivos papéis e posições na vida comunitária. Como pretendo demonstrar neste artigo, a posição "deslocada" das mulheres é um traço constitutivo da experiência social feminina no alto rio Negro, em contraste com a masculina, esta fortemente centrada na noção de "pertencimento". Sendo assim, uma compreensão densa das transformações contemporâneas na vida dos índios da região só se torna possível se considerarmos a diferença entre os pontos de vista de homens e mulheres. 
Partindo desse pressuposto, pretendo discutir o modo como a experiência social feminina vê-se afetada pelas novas configurações sociais que hoje se delineiam no contexto urbano. Para tanto, tomarei por base a análise de uma situação etnográfica muito atual, suscitada pelos casamentos de mulheres indígenas com brancos em São Gabriel. Contudo, antes de adentrar a cidade e explorar o ambiente social que constitui e é constituído por tais casamentos, é preciso trazer à luz alguns elementos da sociocosmologia dos grupos do rio Uaupés, explicitando aqueles que me parecem mais relevantes para a compreensão da forma como são pensadas e experimentadas as relações entre homens e mulheres.

\section{Gênero e socialidade na comunidade ribeirinha}

A bacia do rio Uaupés estende-se sobre os territórios brasileiro e colombiano, compreendendo dezessete grupos étnicos exógamos que seguem uma regra de descendência patrilinear: Tukano, Desana, Kubeo, Wanana, Tuyuka, Piratapuya, Miriti-tapuya, Arapaso, Karapanã, Bará, Siriano, Makuna, Tatuyo, Yuruti, Barasana, Taiwano, Tariana. À parte os Tariana, ${ }^{4}$ todos os outros pertencem à família lingüística tukano oriental. ${ }^{5}$ Os grupos do rio Uaupés integram um sistema regional de intercâmbio matrimonial e de bens, do qual fazem parte também povos pertencentes à família lingüística aruak.

A mitologia de origem da humanidade tem como evento fundamental a viagem de uma grande cobra-canoa, ou "Canoa da Fermentação", rio acima, durante a qual foram originados todos os grupos, fixados os seus territórios primordiais e distribuídas as suas prerrogativas e insígnias de identidade (nomes, mitos, rezas xamânicas, cantos etc). Numa formulação sucinta, pode-se dizer que a mitologia de origem descreve a transformação gradual de uma pré-humanidade em seres humanos com identidade demarcada pelo pertencimento a um grupo exógamo e a unidades clânicas referidas na literatura como sibs. As relações entre os diversos sibs de um grupo exógamo baseiam-se na hierarquia instituída a partir da ordem de nascimento dos seus ancestrais míticos.

Idealmente, há uma correspondência entre o grupo exógamo e o grupo lingüístico. ${ }^{6}$ Devido à regra de exogamia lingüística, um homem deve se casar com uma mulher que fale uma língua diferente da sua, preferencialmente sua prima cruzada patrilateral. Sendo o padrão de residência virilocal, as mulheres casadas de uma comunidade não pertencem a ela por nascimento. O que temos, portanto, é uma situação em que os homens falam a mesma língua e as mulheres falam línguas diferentes. Desse modo, a comunidade local é formada por um grupo de homens agnaticamente relacionados — isto 
é, membros do mesmo sib - suas irmãs solteiras, suas esposas (estrangeiras) e seus filhos. O grupo agnático que compõe a comunidade local possui um lugar específico na hierarquia dos sibs e os membros se casam, idealmente, com mulheres pertencentes a sibs de outros grupos lingüísticos situados no mesmo nível hierárquico (Chernela 1983).

Os valores do parentesco sustentam a convivência entre os moradores da comunidade. Todos devem se tratar como parentes, o que significa, antes de mais nada, compartilhar alimentos, bens e propósitos. Para tanto, é preciso que se conte com um líder forte, capaz de agregar e influenciar os agnatos, neutralizando as disputas políticas e as desavenças pessoais em nome da unidade do grupo. Contudo, a regra de exogamia origina um recorte do grupo local que dispõe, de um lado, os membros do grupo agnático; de outro, as mulheres vindas de fora. O líder da comunidade precisa administrar a tensão latente entre o ideal de coesão do grupo agnático e sua dispersão em unidades auto-referenciadas.

Do mesmo modo como a presença das mulheres estrangeiras é crucial para o processo de produção de pessoas e reprodução da comunidade, a manutenção de um estado de equilíbrio entre os diversos interesses individuais depende em larga medida da postura que elas assumem. Pode-se dizer, portanto, que a possibilidade de se alcançar a meta da boa convivência comunitária (Overing 1991) é, na prática, função da atuação positiva e cooperativa das mulheres casadas. Prevalece, no entanto, a idéia de que os homens têm maior compromisso com o bem-estar coletivo e que as esposas estariam mais predispostas a fazer valer os interesses de sua família conjugal, ou os seus próprios interesses particulares. Em suma, em uma situação de conflito, a lealdade de uma mulher à comunidade de seu marido será prontamente colocada sob suspeita.

O fato de a esposa estrangeira representar uma ameaça à coesão do grupo agnático explica, em parte, a visão da mulher como elemento potencialmente anti-social. Entretanto, o ponto crucial consiste em, no Uaupés, o elemento feminino estar associado à Alteridade e as próprias mulheres do sib serem, em certa medida, concebidas como Outras. Em sua análise da disposição arquitetônica da maloca barasana, C. Hugh-Jones (1979) já mostrava, por exemplo, que às mulheres (solteiras ou casadas) é reservado o espaço mais periférico da casa, e aos homens, representantes do grupo agnático, o espaço do centro. Esse ordenamento espacial traduziria a concepção de que, na comunidade, as mulheres não ocupam a mesma posição estrutural que os homens, independentemente do fato de serem solteiras ou casadas. Comecemos por observar a posição das mulheres casadas, num breve exame da gramática do casamento. 
Antes de mais nada, é importante observar que não há como obrigar uma mulher a continuar casada caso ela não queira, e que nada estaria mais distante da realidade do que imaginar as mulheres como meros objetos de troca a serviço da estratégia política de seus pais e irmãos. Examinando, porém, alguns aspectos que diferenciam as trajetórias conjugais feminina e masculina, podemos supor que o estado "casado" seja mais atrativo para os homens do que para as mulheres. Não se trata de afirmar que as mulheres não desejam se casar, mas sim que os homens possuem mais motivos para insistir em um casamento insatisfatório do ponto de vista afetivo.

Uma vez casadas, as mulheres têm sua carga de trabalho multiplicada e assumem a responsabilidade permanente de alimentar o marido e os filhos. Muito embora atualmente os homens acompanhem suas mulheres com bastante regularidade à roça, a maior parte das atividades relativas ao cultivo e preparo da mandioca possui forte conotação feminina, o que faz com que um homem dependa sempre de uma mulher que lhe prepare a comida. Após a morte da mãe, o solteiro passa a depender das cunhadas, as quais provavelmente já estão sobrecarregadas com as obrigações diárias. Além disso, temendo a competição sexual, os outros homens podem se aborrecer com a presença de adultos solteiros na comunidade. Faz-se assim compreensível a frase de Jean Jackson (1983:128): “[...] os índios do Uaupés acham que todos os homens casariam, se pudessem, e que todas as mulheres poderiam casar, se quisessem".

Outro fator, talvez o mais importante, que torna o casamento menos interessante para as mulheres do que para os homens é o desconforto afetivo que elas experimentam por terem de se apartar dos parentes. Conjugados com a importância que a noção de pertencimento a uma comunidade possui na vida de todo indivíduo, os laços afetivos que unem as mulheres a seus pais, irmãos e irmãs tornam dolorosa a mudança de residência. Quando uma mulher se casa com o filho do irmão de sua mãe (MBS) ou com outro rapaz do grupo local materno, o problema pode ser relativamente atenuado, visto que ela vai residir em uma comunidade onde tem parentes, onde se fala a sua língua. Todavia, para as mulheres que se casam com homens pertencentes a grupos nos quais elas não possuem parentes, torna-se mais difícil atenuar as implicações de morar longe de sua comunidade de nascimento.

Nas conversas cotidianas, as mulheres casadas costumam falar da tristeza de não viver com os parentes. A sensação de deslocamento também é expressa de maneira contundente em certas cantigas rituais femininas cujos textos improvisados costumam fazer referência ao fato de elas não estarem "no lugar certo". Essas cantigas são parte integrante da estrutura litúrgica da cerimônia regionalmente conhecida como Dabucuri, que cele- 
bra o encontro festivo de duas comunidades. Enquanto serve caxiri (bebida fermentada feita à base de mandioca-brava) a uma das convidadas, uma mulher residente na comunidade anfitriã oferece-lhe um improviso, que deverá ser retribuído logo depois que a porção de bebida tenha sido consumida. A cantiga é executada na língua da cantora e, em geral, faz referência à proximidade/ distância entre esta última e os diversos segmentos de sua audiência (Chernela 2003). Os pequenos trechos cantados soam como lamentos. Em uma dessas cantigas, registradas por Chernela (1993:77-78) em uma comunidade wanana, duas mulheres tariana se alternavam para falar sobre o fato de viverem "misturadas": "[...] nós sofremos. Nascemos para ficar junto de nossos pais. Nascemos para sofrer assim. Minha irmã menor, nós que padecemos, só as mulheres tariana passam tristeza assim. Atadas aos lugares, cheias de sofrimento".

A exterioridade das mulheres também aparece como um tema recorrente nas cantigas femininas analisadas por Piedade (1997) em uma comunidade de homens tukano. As cantoras percebem-se deslocadas em meio aos parentes do marido, como fica claro no seguinte trecho de uma das performances registradas pelo autor: "Como sou mulher, vivo perdida por aqui, vivo perdida por aqui. Se fosse homem, viveria nas terras de meu pai, transformada em esteio eu estaria" (Piedade 1997:86).

Por outro lado, o casamento também traz vantagens importantes para as mulheres. No que diz respeito à micro-política da vida diária, favorece o incremento da autonomia feminina. Uma característica marcante das relações entre os sexos no Uaupés é justamente a autonomia substantiva de que gozam as mulheres casadas. A participação na escolha do cônjuge, a possibilidade de abandonar o marido sem grandes conseqüências nas fases iniciais do casamento, antes do nascimento dos filhos e, principalmente, o domínio exclusivo sobre uma esfera importante da economia doméstica constituem recursos importantes para o exercício da agência feminina, sobretudo no âmbito das relações conjugais propriamente ditas. O alto grau de especialização e investimento que cerca as atividades executadas exclusivamente pelas mulheres e a importância dos produtos da roça no dia-a-dia da família nuclear e da comunidade permitem às esposas valerem-se de sua capacidade de trabalho como moeda de negociação com os maridos. Em suma, a mulher casada detém habilidades das quais depende o bem-estar cotidiano dos moradores da comunidade; ela sempre pode valer-se disso para afirmar sua posição diante do marido e de seus agnatos.

Esse ponto faz-me recordar o comentário de uma viúva que atualmente reside com o irmão solteiro em um sítio próximo à cidade de São Gabriel. $\mathrm{Na}$ ocasião, ela me falava sobre a saudade da mocidade, do marido e da 
vida em comunidade. Dizia que "o finado" havia sido um grande pescador e que, nos tempos de casada, ela vivia muito bem, nada lhe faltava, era um tempo de abundância. Quando argumentei que o irmão também parecia um homem trabalhador, ela me respondeu: "E de que adianta? Irmão é diferente de marido. A gente não pode mandar nele".

\section{Mulher e alteridade}

É preciso agora abrir um parêntese para esclarecer melhor a aproximação conceitual aqui postulada entre mulher e alteridade no rio Uaupés. A questão que se coloca primeiramente é a seguinte: se as esposas estrangeiras representam a Alteridade, pelo fato de pertencerem a grupos afins, o que dizer das irmãs? Pois se elas também são em alguma medida Outras, não o são do mesmo modo, nem pelos mesmos motivos que suas cunhadas. Em que diferem, então, as respectivas posições das mulheres solteiras e casadas de uma dada comunidade?

Entre os grupos do rio Uaupés, a dinâmica da identificação e da diferenciação desenrola-se a partir de dois processos distintos. O primeiro, que diferencia os grupos agnáticos entre si pela conexão vertical de cada um com seus respectivos ancestrais, atualiza-se pela transmissão patrilinear de nomes cerimoniais (provenientes da segunda geração ascendente) e pela reafirmação ritual desse vínculo. Dependendo do grupo, o nome cerimonial (em Tukano, basé'ke wame) pode ser transmitido à criança assim que ela nasce ou logo depois que ela começa a andar e falar (S. Hugh-Jones 2002:26), conferindo-lhe a alma-espírito que a conectará à sua linhagem agnática. Através da posse do nome/ alma proveniente da genealogia do sib, a criança passa a partilhar da essência espiritual do mundo ancestral, efetivando-se, assim, sua vinculação ao grupo de descendência paterno. É nesse sentido que podemos afirmar que a esposa estrangeira representa a "diferença" dentro da comunidade. Ela porta um nome proveniente de outro grupo, partilha de outra essência espiritual. Por isso, ela será sempre uma afim. A irmã, por sua vez, será sempre uma consangüínea: a identidade espiritual com os agnatos é preservada ao longo de toda a vida, e ela jamais deixa de pertencer ao grupo em que nasceu, e pelo qual pode traçar sua conexão espiritual com o mundo mítico.

O segundo processo de identificação e diferenciação desenrola-se no âmbito das relações cotidianas. Com base na co-residência, na convivência diária e na partilha de alimentos com os outros moradores, as mulheres estrangeiras vêem-se atraídas para dentro, por meio de processos de con- 
substanciação. Nesse sentido, o destino da esposa é aparentar-se. A irmã, por seu turno, percorre trajetória inversa. Mais cedo ou mais tarde, ela deixará sua comunidade para residir num grupo estranho, com o qual vai conviver e para o qual vai gerar filhos. O destino da irmã é desaparentar-se. Deixando de lado considerações de ordem afetiva e observando a questão de um ponto de vista formal, podemos dizer que a produtividade da mulher solteira para a reprodução do grupo concentra-se em seu caráter de ligação com os outros. Somente na geração seguinte, quando sua filha (idealmente) voltará como esposa do filho de seu irmão, ${ }^{7}$ a capacidade criativa da mulher que saiu se torna efetiva para a continuidade de sua linhagem agnática (C. Hugh-Jones 1979).

Por tudo isso, é possível dizer que a posição da mulher solteira é marcada por uma assimetria em relação a seus germanos do sexo masculino e que, se há um domínio das relações interpessoais em que a assimetria de valor entre os sexos se atualiza de forma mais eloqüente, é o da relação entre irmão e irmã. No âmbito da comunidade local, a tensão entre interior e exterior sempre incide sobre as mulheres, sejam irmãs ou esposas, mas é em relação às primeiras que ela se materializa sem disfarces: enquanto os roteiros da vida cotidiana se encarregam de dissimular a diferença entre marido e mulher, para que a comunidade exista e o processo do parentesco siga seu curso é necessário que a irmã vá embora.

A seguinte situação, observada em uma comunidade do rio Uaupés, ilustra bem esse ponto. Na refeição após uma pescaria coletiva com timbó, homens e mulheres posicionaram-se em pólos opostos do centro comunitário. Porém, a comunidade dividiu-se em três grupos, e não em dois: homens (solteiros e casados), mulheres casadas e mulheres solteiras. Os homens, não importando se jovens ou velhos, casados ou solteiros, comiam todos juntos, perto da porta principal, chamada "porta dos homens", ao passo que as mulheres solteiras ficaram mais próximas à "porta das mulheres", localizada nos fundos da edificação. No meio situavam-se as mulheres casadas.

Resumindo, o desafio crucial da vida comunitária no Uaupés é assimilar produtivamente o exterior, de maneira tal que o afastamento diferencial entre os grupos afins possa ser permanentemente atualizado. Contudo, ao tomarmos o ponto de vista das mulheres, torna-se inevitável indagar como elas vivenciam o fato de estarem sempre marcadas pela condição de Outro. Com essa questão em mente, prossigo no propósito de desvelar um pouco mais a perspectiva feminina, concentrando minha atenção nas percepções e experiências de mulheres que deixaram suas comunidades ribeirinhas para viver na cidade de São Gabriel, onde a noção de "deslocamento" parece se deslocar no eixo sexual, como veremos. 


\section{Da comunidade à cidade}

Antigo território de índios baré, a cidade de São Gabriel da Cachoeira, sede do município de mesmo nome, localiza-se a $853 \mathrm{~km}$ de Manaus, numa região rodeada de serras que guardam grande número de referências mitológicas para os grupos indígenas.

Desde 1759, com a implantação de um forte militar, o território onde se localiza a cidade foi palco de diversos programas de ocupação estratégica da região por parte dos brancos - agentes coloniais leigos e missionários. De um modo geral, durante um longo período, os brancos pautaram suas relações com as populações nativas pelo objetivo de tirar proveito de sua força de trabalho. A memória coletiva indígena é povoada por lembranças de episódios de aldeamentos e descimentos forçados, do sistema de dívidas com patrões, e da intolerância clerical para com os costumes indígenas (Wright 1991, 1992; Meira 1994, 1996).

Os últimos trinta anos, porém, assistiram à crescente reorganização política dos povos do alto rio Negro. Estes passaram a lutar pela demarcação de suas terras ${ }^{8}$ e pelo direito à preservação de sua cultura, que havia sido sistematicamente afrontada pelos salesianos durante as primeiras décadas do século XX. Também durante este período, São Gabriel passou por um acelerado processo de urbanização e crescimento populacional. Não vou me deter aqui na descrição desse processo, já suficientemente detalhado em outras fontes (Santos 1988; Oliveira 1995; Lasmar 2005). O importante é destacar que foi nesse período que se deu a entrada dos "peões", trabalhadores de origem pobre que, dentre os brancos, vieram a desenvolver relações de convívio mais estreito com os índios.

Atualmente, há cerca de 15 mil pessoas residindo em São Gabriel, das quais $80 \%$ se consideram indígenas. Boa parte da população (aproximadamente $44 \%$ ) é originária das comunidades situadas nas cinco Terras Indígenas que circundam a cidade. ${ }^{9}$ As principais motivações alegadas pela população indígena das comunidades para a mudança para o contexto urbano são a busca por educação escolar e trabalho remunerado, ambas referindo-se a processos de relacionamento com os brancos. Com efeito, como demonstrei em outro trabalho, o movimento da população do rio Uaupés em direção à cidade só adquire sentido à luz das concepções dos índios acerca dos brancos e das cidades de um modo geral. A escola, as mercadorias e a medicina ocidental devem ser entendidas como epítomes de tais capacidades, as quais, crêem os índios, podem ser experimentadas e apropriadas de modo mais imediato no contexto urbano (Lasmar 2005).

A importância hoje conferida pelos índios do rio Negro à educação escolar deve-se muito ao relacionamento de quase um século com a Missão 
Salesiana. Imbuídos da tarefa de catequizar e civilizar a população indígena, principalmente as crianças e os adolescentes, os salesianos estabeleceramse na região em 1917 e formaram várias gerações de alunos em regime de internato. Com o corte de verbas federais no início dos anos 1980, o sistema de internato teve de ser gradativamente desativado. Diante disso, e para que os alunos pudessem completar os estudos, muitas famílias trataram de viabilizar moradia em São Gabriel. ${ }^{10}$

O segundo motivo alegado pelos índios para a mudança para São Gabriel, a busca de trabalho remunerado, possui, na maioria dos casos, relação direta com a busca por educação escolar. Para muitas famílias recém-chegadas à cidade, cuja sobrevivência depende inteiramente da produção obtida na roça, é preciso muito empenho para manter os filhos na escola. Por um lado, é necessário arcar com uma série de custos, como material didático e uniforme. Por outro, a rotina escolar dificulta a preparação das crianças para o trabalho agrícola e as outras atividades produtivas tradicionais, subtraindo das famílias um importante contingente de força de trabalho. Logo, para que seja possível estabelecer-se na cidade, manter os filhos na escola e equipar o domicílio com as mercadorias necessárias é crucial que pelo menos um membro do grupo doméstico exerça uma atividade remunerada. Ainda assim, segundo dados recentes, 15\% dos domicílios da cidade não possuem nenhum morador com renda fixa mensal (ISA 2005).

A população de São Gabriel apresenta hoje uma configuração social razoavelmente complexa. O fluxo de famílias indígenas do interior em direção à cidade é contínuo, e o modo de inserção dos índios na paisagem urbana varia de acordo com uma série de fatores, dentre os quais destacam-se o acesso a lotes agrícolas e/ ou a uma ocupação remunerada e a possibilidade de contar com o apoio material de parentes na cidade. Simplificando um pouco o cenário, podemos dizer que as famílias residentes em São Gabriel há mais tempo costumam ter mais acesso ao mercado de trabalho, enquanto os recém-chegados precisam recorrer à atividade agrícola como principal meio de subsistência. Numa escala de inserção no modo de vida tipicamente urbano, os dois extremos seriam representados, de um lado, por famílias indígenas com uma renda que lhes permite manter os filhos na escola sem dificuldades e adquirir as mercadorias necessárias; de outro, por famílias sem renda alguma ou com uma que não atende às exigências mínimas da vida na cidade. Para as últimas, instalar-se na casa de parentes e conseguir destes autorização para cultivar um terreno em sua propriedade na região periurbana tem sido uma estratégia comum de sobrevivência nos primeiros tempos de residência na cidade (Eloy \& Lasmar 2007). 


\section{Transformações no modo de vida}

Os moradores de São Gabriel costumam referir-se à diferença entre a vida na comunidade e na cidade em termos de uma distinção primordial entre índios e brancos. Para tanto, tomam por base suas interpretações da mitologia de origem, mais precisamente do momento do mito em que ocorre a diferenciação entre índios e brancos e estes últimos dão mostras de seu temperamento agressivo e ousado (Lasmar 2005). Coadunando-se com o ethos pacífico e moderado dos índios, a vida comunitária teria por característica principal a valorização do parentesco, da partilha e do bem comum. Na cidade, por sua vez, os desejos e objetivos se tornariam mais individualizados, e a competição passaria a ser a regra. Comunidade e cidade representariam, portanto, dois modos distintos de viver, que traduziriam filosofias sociais distintas.

Não obstante o nítido contraste entre cidade e comunidade, para os índios de São Gabriel haveria formas distintas de estar na cidade: há aquelas mais próximas do modo branco de viver e outras mais vinculadas ao modo indígena (isto é, mais próximas da vida na comunidade). Por um lado, a existência de modos diversos de estar na cidade poderia ser observada comparando-se famílias recém-chegadas a São Gabriel com famílias que residem ali há mais tempo, por outro, comparando-se gerações no interior de uma mesma família. Qualquer que seja a situação socioeconômica de sua família, quanto mais jovem é uma pessoa, mais distante ela fica do modo de vida dos parentes que permaneceram na comunidade.

As mulheres indígenas criadas na cidade percebem-se distanciadas das recém-chegadas pelo fato de levarem uma vida mais próxima do modo de vida propriamente urbano. Estão inseridas no mercado de trabalho e freqüentam, com desenvoltura, os mesmos ambientes que os brancos vindos de fora. $\mathrm{Na}$ escala de diferenciação de estilo de vida a partir do modelo "branco", elas se vêem ocupando uma posição intermediária, "índias" em contraste com a mulher branca ou a cabocla nascida na cidade, "brancas" (ou menos índias) em comparação com a moradora da comunidade ribeirinha.

O tipo de trabalho exercido por uma mulher determina, em larga medida, sua rotina de interações sociais. As mulheres que cresceram na cidade e passaram boa parte de sua infância e adolescência nos bancos escolares não costumam depreciar o trabalho agrícola; ao contrário, é até com certo embaraço que assumem jamais ter ido à roça. Observando suas parentas mais velhas, elas compreendem que esse tipo de atividade pode ser uma fonte poderosa de orgulho e auto-estima feminina. No entanto, a roça e todo o conjunto de valores a ela associado articulam uma representação da identidade feminina que não corresponde aos seus anseios. Tendo aprendido a 
projetar suas expectativas de futuro na direção apontada pela escola, essas mulheres investem seu tempo no exercício de ocupações mais qualificadas quanto ao nível de escolaridade. Nesse sentido, elas se percebem distanciadas tanto de suas mães e avós nascidas e criadas nas comunidades quanto das mulheres de sua própria geração recém-chegadas à cidade.

Um fator importante no processo de transformação do modo de vida é a maior freqüência de interação com os brancos. No contexto urbano, a população indígena passa a conviver de maneira mais intensa com brancos das mais variadas procedências - militares lotados nos pelotões do Exército, funcionários públicos e de ONGs, missionários católicos e evangélicos, ex-garimpeiros e descendentes das famílias de tradição no comércio e de influência na política local, muitas das quais ali chegaram em época anterior à explosão populacional de São Gabriel. Um dos efeitos dessa convivência é o estabelecimento de parcerias sexuais e, não raramente, de vínculos conjugais entre as mulheres indígenas e os brancos.

\section{Irmã e esposa}

No processo de transformação do modo de vida de uma mulher, o casamento com um branco exerce um papel crucial. Ele a aproxima do modo "branco" de viver, uma vez que cria um contexto privilegiado para a realização de novos roteiros e o desempenho de novos papéis (Lasmar 2005:182-188). Do ponto de vista da estrutura da aliança, este pode ser visto como um casamento "distante", que atende à necessidade de ampliar a rede de afinidades de uma família para fazer frente às demandas de um novo tempo (Lasmar 2005:105-115). Ter uma filha casada com um branco facilita o acesso ao mundo da cidade, do hospital, da escola e das mercadorias. Contudo, na maior parte dos casos, a própria opção por um marido branco já é sinal de um estilo de vida em processo de alteração.

A aliança matrimonial em São Gabriel é um "assunto de família" e envolve, entre outras coisas, concepções de identidade, avaliações de prestígio, noções de pertencimento a grupos sociais, interesses econômicos. Afirmar isso não significa, de modo algum, subtrair às mulheres a capacidade de agência de que elas efetivamente dão mostras quando escolhem um marido branco. Muito pelo contrário: perceber as mulheres como agentes de suas próprias escolhas depende justamente de compreender de que modo tais escolhas são infletidas pelo sistema de relações sociais no qual elas se movem e se constituem como sujeitos.

As uniões conjugais entre mulheres indígenas e homens brancos são um assunto palpitante em São Gabriel. Como elas não se inserem em uma 
estrutura de aliança recíproca — pela irmã que se dá, em troca não se recebe mulher alguma — os índios consideram que os brancos estão "roubando" suas mulheres. Além dessa ruptura no sistema de troca matrimonial, o casamento com um branco introduz ainda um outro tipo de descontinuidade na estrutura tradicional de aliança. Enquanto esta última prevê o casamento entre pessoas de mesmo status social, isto é, de mesma posição na hierarquia interna dos grupos exógamos (Chernela 1983), o casamento com um branco não só é, ele próprio, uma espécie de união assimétrica - se tomarmos como referência o sistema social urbano - como institui uma assimetria de perspectiva matrimonial entre germanos de sexo diferente, que passam a ter possibilidades diferenciadas em relação a seus casamentos. Explico-me: se as mulheres mais adaptadas à vida urbana tendem a se casar com brancos, seus irmãos, que possuem um estilo de vida semelhante ao delas, precisam buscar namoradas e esposas entre as índias recém-chegadas à cidade ou entre as moradoras de comunidades ribeirinhas, uma vez que as moças com as quais convivem estão relativamente indisponíveis. Poderíamos dizer, assim, que a jovem que se casa com um branco realiza uma união hipergâmica, enquanto seu irmão tende a se casar com uma mulher situada em patamares inferiores na escala de classificação social que vigora na cidade e que diferencia as pessoas de acordo com seu modo de vida.

Seguindo esse raciocínio, veremos que a assimetria de perspectiva matrimonial deve se reproduzir na geração seguinte. Filhos de germanos de sexos diferentes possuirão modos de vida diferenciados e possibilidades matrimoniais diversas. Tomemos o exemplo de um casal de irmãos que chegou a São Gabriel ainda na infância. Chamemo-los de Carlos e Maria. Carlos casa-se com uma mulher recém-chegada do interior e Maria une-se a um homem branco. O filho de Carlos não se casará com a FZD (filha da irmã do pai), mulher à qual ele teria direito por tradição, pois, repetindo o que ocorreu com sua própria mãe, a jovem em questão vai realizar um casamento hipergâmico, muito provavelmente com um branco. A filha de Carlos poderia se casar com o filho de Maria (FZS), pois, nesse caso, ela estaria se casando para cima. Porém, devido à presença dos brancos no mercado matrimonial, na cidade, o casamento de primos cruzados perde sua qualidade de transação preferencial e, por isso, o casamento da filha de Carlos com o filho de Maria torna-se tão provável quanto qualquer outro que siga o mesmo padrão de hipergamia para as mulheres e hipogamia para os homens.

Por tudo isso, a preferência das mulheres pelos brancos torna-se motivo de ressentimento para os homens, sobretudo para os jovens solteiros. Para os pais da moça, ter um genro branco traz muitas vantagens. Devido à sua situação econômica mais confortável, a filha pode abastecê-los com 
bens duráveis, mercadorias, remédios. É bem verdade que esses benefícios estendem-se a uma vasta gama de parentes, inclusive irmãos, mas nem por isso estes deixam de se sentir lesados pelo casamento da irmã. Via de regra, eles se posicionam contra a união, podendo apresentar dificuldades de relacionamento com o cunhado. Consumado o casamento, em muitos casos hesitam em aceitar o marido da irmã como membro da parentela.

Todavia, o genro branco costuma contar com a cumplicidade contumaz da sogra, que alega que os pretendentes indígenas não seriam capazes de dar conforto material à mulher e aos filhos. Ancoradas na opinião da mãe, que quase sempre traz a reboque o consentimento do pai, as jovens depositam no casamento com um branco suas expectativas de futuro e a figura do afim não-indígena passa a fazer parte da vida de muitas famílias de São Gabriel. Entre a população residente na cidade há mais de uma geração esse tipo de casamento é um fenômeno trivial.

Além de resultar com certa freqüência em uniões matrimoniais, a preferência das mulheres pelos brancos possui ainda outras conseqüências importantes. Em São Gabriel, é elevado o número de crianças sem paternidade reconhecida e crescente o número de celibatários entre os homens indígenas. Quando perguntadas sobre o porquê da preferência pelos brancos, as moças nascidas na cidade lançam mão de dois tipos de argumento. O primeiro é o de que os rapazes indígenas são mais retraídos, não sabem seduzir, não se insinuam "nem mesmo para conversar". Esse juízo é, de certo modo, compartilhado pelos homens indígenas, que costumam dizer que os brancos têm mais "lábia" e, por isso, mais sucesso quando se trata de conquistar as mulheres. O segundo argumento das jovens é o de que os índios bebem cachaça de forma desmedida, tornando-se briguentos e inconvenientes nas festas e clubes noturnos.

O consumo desenfreado de cachaça é apontado pelas mulheres como um dos problemas mais graves enfrentados pelas famílias indígenas na cidade. É praticamente impossível encontrar uma que não o conheça de perto. Com efeito, não é incomum que os homens gastem boa parte do dinheiro ganho com seu trabalho nas noitadas que prolongam a ingestão de cachaça, comprometendo o orçamento familiar, em muitos casos gravemente. Além disso, o estado de embriaguez é citado como a maior causa de violência doméstica e fonte permanente de conflito entre os cônjuges. As mulheres reclamam que, quando alcoolizados, seus maridos tornam-se irascíveis e agridem-nas pelos motivos mais banais.

A ingestão de cachaça associa-se também à prática de pequenos delitos e à violência juvenil. Já há algum tempo, os moradores de São Gabriel lidam com o problema da existência de gangues de adolescentes que, alcoo- 
lizados, agridem os transeuntes durante a madrugada sem motivo aparente. Os adultos vêem a ingestão desregrada de cachaça como conseqüência da falta de perspectiva para os jovens indígenas. ${ }^{11}$ Entre as possíveis causas dessa situação, eles citam a situação econômica precária das famílias que chegam a São Gabriel para fixar residência, a dificuldade enfrentada pelos índios para competir com os brancos no mercado de trabalho e conseguir uma boa remuneração profissional, e a posição secundária dos homens indígenas no esquema de preferências sexuais e matrimoniais das mulheres. O fato é que, inseridos realmente de forma desprivilegiada em um sistema social que garante aos brancos acesso mais fácil ao dinheiro, às mercadorias e às mulheres, os jovens indígenas retraem-se, diminuindo ainda mais suas chances de namorar as moças da cidade. Esse retraimento pode ser visualizado na distribuição espacial dos jovens na pista de dança dos clubes noturnos, por exemplo. Os rapazes indígenas, principalmente os recém-chegados, costumam dançar juntos em grupos masculinos, embriagando-se progressivamente, enquanto as moças interagem com os brancos. Em São Gabriel, depois dos brancos vindos de fora, as alternativas locais preferenciais das moças para parceiros sexuais ou matrimoniais são os militares nascidos na região, brancos ou índios — nessa ordem. Assim, se é possível encontrar uma moça nascida na cidade com namorado ou marido indígena, é muito provável que se trate de um militar.

\section{A gramática dos casamentos com brancos}

Para que possamos nos aproximar de uma compreensão da preferência das mulheres pelos brancos, precisamos focalizar o sistema de relações em que se definem as suas possibilidades de agência. Compreender a experiência social da mulher casada com um branco implica compreender tanto a sua posição como esposa quanto a sua situação no círculo de relações que se irradia a partir da família consangüínea.

A estrutura da relação conjugal nos casamentos com brancos é muito distinta daquela que vimos nas uniões entre homens e mulheres indígenas no rio Uaupés. Na comunidade ribeirinha, as mulheres valem-se da importância de suas capacidades produtivas e reprodutivas para sustentar o seu ponto de vista sobre questões que afetam a vida conjugal e familiar. Além disso, a complementaridade econômica entre marido e mulher fornece a base para o desenvolvimento de uma relação de cumplicidade que, com o passar do tempo, tende a se tornar cada vez mais estável.

A esposa de um branco, por sua vez, possui meios mais limitados para afirmar sua perspectiva. Do ponto de vista econômico, o marido depende 
menos dela do que ela dele. Essa maior independência dos maridos brancos reproduz-se no plano afetivo-sexual. Os brancos de São Gabriel transitam em um circuito de relações na cidade do qual a esposa indígena raramente participa. A partir dos depoimentos de mulheres casadas com brancos por um período de uma a duas décadas, percebi um processo comum de desenvolvimento da relação conjugal caracterizado pelo distanciamento gradativo entre os cônjuges. Depois dos primeiros tempos do casamento, com o abrandamento da paixão sexual, o marido torna-se mais disperso e menos integrado à rotina da casa, passando a ser visto em bares da cidade na companhia de outras mulheres. As escapadas vão se tornando mais freqüentes e sua ausência constante esfria a relação do casal. Insatisfeitas com a atmosfera de distanciamento que impregnou a relação, elas muitas vezes cogitam a separação, mas na maioria dos casos recuam devido ao receio de que os filhos fiquem desamparados ou de que a família consangüínea passe por privações. A esta altura, uma série de necessidades já foi criada e precisa ser continuamente satisfeita.

Por outro lado, afora os benefícios econômicos, o casamento com um branco oferece à mulher a possibilidade de permanecer perto de seus pais e irmãos. Assim, além de gozar de uma situação financeira privilegiada, que lhe permite ajudar os familiares, a esposa de um branco não se vê deles apartada, tampouco dividida em suas lealdades a consangüíneos e afins. Ao contrário, o papel de arrimo de família torna a sua casa um pólo de convergência para parentes paternos e maternos. E mesmo nos casos mais raros em que a família do marido mora em São Gabriel, a tendência é que a mulher mantenha uma convivência cotidiana mais estreita com os seus próprios parentes. Quando na cidade, seus pais passarão boa parte do tempo em sua casa, cuidando dos netos enquanto ela se ausenta para trabalhar. Daí uma reclamação freqüente dos brancos: eles costumam dizer que casar com uma mulher indígena é como casar com uma comunidade inteira.

As mulheres casadas com brancos desempenham um papel muito importante no processo de fixação dos parentes na cidade e na transformação de seu modo de vida. Nesse sentido, podemos dizer que os casamentos com brancos potencializam a capacidade de agência das mulheres no que se refere aos processos de produção de identidade no âmbito da família extensa consangüínea, operando uma espécie de inversão na assimetria que vimos caracterizar as relações entre irmão e irmã no rio Uaupés. Ocupando uma posição estratégica no sistema social urbano, elas atuam como elos entre os recém-chegados das comunidades ribeirinhas - que têm na sua casa um importante ponto de apoio - e o mundo dos brancos. 
Porém, a vantagem da esposa de um branco frente a seus irmãos não decorre exclusivamente da condição econômica de que passa a gozar e que lhe permite ajudar os parentes e aglutiná-los em torno de si. Na cidade, há um outro campo de ação em que as mulheres costumam fazer valer uma perspectiva alternativa em relação ao processo de reprodução social. Tratase da prática, por sinal bastante polêmica, de dar um nome cerimonial às crianças nascidas de uniões com os brancos.

\section{Crianças misturadas}

A identidade das crianças nascidas dos relacionamentos entre índias e brancos é objeto de controvérsia em São Gabriel, ensejando um conflito de perspectivas. Inicialmente, os índios afirmam que tanto os filhos de mulheres indígenas com homens brancos quanto os filhos de homens indígenas com mulheres brancas são "morégi", que significa "misturado". "Morégi" é por vezes traduzido como "caboclo", mas os informantes não parecem realmente confortáveis com o emprego deste último termo para referir-se à identidade das crianças "misturadas". A inadequação do termo "caboclo" para dar conta da identidade dessas crianças pode ser explicada pelas próprias concepções nativas acerca do processo de reprodução da identidade étnica e, por extensão, indígena.

Como já expliquei acima, de acordo com a teoria da pessoa entre os grupos do rio Uaupés, a alma da criança — o sopro de vida, o princípio vital é-lhe transmitida inteiramente pelo pai, através do nome cerimonial que ela recebe ao nascer. É pela posse do nome/ alma da genealogia do sib que se efetiva a vinculação ao grupo de descendência paterno. Nesse sentido, a diferença entre o filho de mãe indígena com pai branco e o filho de pai indígena com mãe branca é que, a rigor, o primeiro está privado do direito de portar um nome indígena. Conseqüentemente, embora ambos sejam "misturados", somente o segundo poderia ser considerado "índio". Nesse registro, portanto, o acesso legítimo a uma alma indígena é o que determina a identidade de "índio".

Em conformidade com o sistema de descendência patrilinear, o filho de índia com branco é dito pekâsa morégi (branco misturado), enquanto o filho de índio com branca, caso muito mais raro, é definido como po'teríkihi morégi (índio misturado). ${ }^{12}$ Suponho que o termo "morégi" faça aqui as vezes de um qualificador, não sendo o foco semântico da definição de identidade, o que explicaria a inadequação do termo "caboclo" para dar conta do caso. Enquanto "caboclo" não significa nem índio nem branco, referindo-se a 
uma terceira categoria, os filhos de branco com índia seriam "brancos", mas de um tipo específico, enquanto os filhos de índio com branca seriam "índios" de um tipo especial. A especificidade de ambos seria determinada pela característica que compartilham - corpos misturados.

Grande parte da polêmica em torno da identidade dos filhos de brancos tem origem no fato de que, contrariando a tradição, eles também acabam recebendo um nome cerimonial, a fim de que possam ter a saúde protegida ao longo da vida por meio dos ritos xamânicos apropriados. Na falta de um pai indígena, o nome provém do sib do avô materno, o que faz com que a criança seja identificada com a etnia da mãe. Embora ela seja considerada "misturada", do ponto de vista de sua mãe, sua avó e seu avô materno - que nomeia o bebê a partir de um de seus irmãos ou irmãs a criança tem assegurada a posse de uma alma indígena pelo nome. Apesar de não dispor de dados estatísticos, meu palpite é que se trata de uma prática habitual.

As mulheres costumam minimizar o caráter heterodoxo dessa prática e parecem mesmo naturalizá-la, com comentários do tipo: "Meus filhos são misturados: meio índios, meio brancos. Então, a parte indígena deles é Tukano, como eu". Ao mesmo tempo, elas sustentam ser imprescindível que à "parte indígena" do corpo da criança esteja atrelado um nome indígena. O raciocínio é perfeitamente coerente com a idéia de que, para ser "índio" (em oposição a "branco"), é preciso descender de um dos ancestrais que desembarcou e se fixou no Uaupés depois da grande viagem original, o que se atualiza através da posse de uma alma/ nome. No entanto, demonstra uma desatenção ao princípio patrilateral firmemente defendido pelos homens.

Em geral, os tios maternos rejeitam o esquema, considerando-o ilegítimo, e argumentam que o direito a portar esses nomes seria apenas de seus próprios filhos. Vejamos um caso que ilustra bem o tipo de conflito que pode resultar desta situação. Depois de uma relação temporária com um homem branco, uma jovem tukano solteira, que residia na cidade em companhia do irmão, deu à luz uma criança. Como seu pai estava morando muito longe dali, ela pediu ao irmão que benzesse o sobrinho, dando-lhe um nome tukano. Alegando que o bebê era filho de um branco, ele se recusou a fazêlo. Passado um ano, a criança contraiu uma doença grave e incurável, cuja origem é creditada, pelos parentes, ao fato de não ter sido benzida quando bebê. Nesse caso específico, a mulher teve de ceder frente à resistência do irmão, o que provavelmente não teria acontecido se à época do nascimento da criança tivesse podido contar com o apoio de seus próprios pais para dar ao bebê um nome cerimonial. 


\section{Considerações finais}

O casamento com brancos re-situa socialmente as mulheres. Além de dotá-las de recursos materiais que lhes permitem ajudar os parentes e atraí-los para suas casas, ele cria uma situação propícia para que elas transmitam aos filhos os nomes de seus antepassados. Lembremos, porém, que isso só é possível se as mulheres puderem contar com a conivência de seus próprios pais ou de outro homem de seu próprio sib, pois o conhecimento xamânico necessário à realização do ritual de nominação é prerrogativa masculina. É intrigante o fato de os avós maternos da criança compactuarem regularmente com uma prática onomástica que transgride o sistema tradicional de reprodução dos grupos indígenas. Ao dar ao filho de sua filha um nome que, por direito, pertenceria apenas aos filhos de seus filhos de sexo masculino, o avô materno está, de certo modo, promovendo a dissipação de algo concebido como um bem que deveria permanecer no interior de sua própria linha agnática. Nestas considerações finais quero chamar a atenção para a situação mais ampla que cria as condições de estabilidade desse tipo de "transgressão", permitindo que ela se torne possível e legítima também do ponto de vista do avô materno. Sugiro que a transferência matrilinear de nomes, assim como, de uma maneira geral, a reformulação da posição subjetiva das mulheres, seja entendida como parte de transformações mais amplas nos regimes de socialidade dos índios do alto rio Negro.

A transferência matrilinear de nomes parece indicar uma flexibilização da própria noção de descendência patrilinear em favor de uma versão cognática, resultante, a meu ver, da orientação global dos índios em direção ao mundo dos brancos. A identidade do grupo agnático, sua atualização como unidade discreta, só se realiza na afirmação de suas diferenças em relação aos outros. Não obstante, o surgimento de uma identidade indígena panétnica é um fato cada vez mais evidente. Tome-se como exemplo a crescente organização político-burocrática dos grupos do rio Negro em associações políticas que representam comunidades localizadas em uma determinada faixa geográfica, sem consideração direta à filiação ética ou de sib.

Essa tendência ao estabelecimento de uma identidade indígena genérica realiza-se de maneira mais radical em São Gabriel. As formas urbanas de territorialidade favorecem a convivência entre pessoas de etnias diversas e limitam, em boa medida, as possibilidades de se recriarem na cidade as condições sociocosmológicas necessárias para a atualização ritual das diferenças entre os grupos. Embora esta diferença esteja muito longe de se dissolver - como atesta a estabilidade da regra de exogamia lingüística (Lasmar 2005) mesmo no contexto urbano - estamos diante de uma situação 
em que o foco da alteridade passa a recair mais diretamente sobre a figura do branco, um Outro diferente dos outros. ${ }^{13}$ Tendo em vista o que venho descrevendo como o "[...] movimento dos índios em direção ao mundo dos brancos [...]" (Lasmar 2005), e o processo, dele decorrente, de constituição de uma identidade pan-étnica no alto rio Negro, esse deslizamento da posição de alteridade nada tem de surpreendente. Da mesma forma, não deve nos surpreender que, neste cenário de intensas transformações, a posição das mulheres também deslize, abrindo novas possibilidades de agenciamento das relações de parentesco e aliança.

Recebido em 11 de setembro de 2007

Aprovado em 11 de junho de 2008

Cristiane Lasmar é doutora em antropologia pelo PPGAS-MN-UFRJ, atualmente pós-doutoranda (CNPq) no PPGSA do IFCS-UFRJ, em que realiza atividades de pesquisa, ensino e extensão. E-mail: <cristianelasmar@gmail.com> 


\section{Notas}

* Este artigo sintetiza, aprofunda e revisa questões discutidas de maneira mais dispersa em trabalhos anteriores (Lasmar 1998, 2002, 2005). Os dados etnográficos apresentados são provenientes da literatura etnológica sobre a região e de uma longa experiência de pesquisa na cidade de São Gabriel da Cachoeira, iniciada em 1996.

${ }^{1}$ Para uma descrição compreensiva e densa dos rituais de iniciação masculina entre os Barasana do rio Pirá-Paraná, alto Uaupés, ver S. Hugh-Jones (1979).

${ }^{2}$ É particularmente ilustrativo o caso do movimento indígena, atualmente um dos principais contextos de agenciamento dessas relações. Meu ponto aqui é simples: uma mulher dificilmente ocupará posição de liderança na política das associações indígenas do alto rio Negro, a não ser no âmbito das associações fundadas e compostas exclusivamente por mulheres, cujo viés de gênero costuma ser explicitado no próprio nome.

${ }^{3}$ Um relato da índia tuyuka Catarina Borges sobre o seu próprio ritual de iniciação feminina encontra-se hoje publicado no livro Marya dita Iñan $\neg n \neg$ seMasir, de autoria dos Tuyuka, para servir como material de leitura na escola. O livro foi produzido dentro do Projeto de Educação Indígena/FOIRN-ISA. A associação entre o trabalho produtivo na roça e a maternidade pode ser demonstrada, por exemplo, na seguinte frase, que Catarina diz ter ouvido dos velhos durante o ritual: "Fique sentada, resguarde muito bem, pois tu és mulher, provedora de alimento, mãe das plantações, resguarde [...]". Agradeço a Flora Cabalzar a indicação e a tradução do texto da língua tuyuka para o português.

${ }^{4} \mathrm{O}$ idioma original dos Tariana é da família aruak, mas hoje eles falam majoritariamente o tukano.

${ }^{5}$ É necessária uma distinção terminológica: entre a família lingüística tukano (oriental) e a língua tukano propriamente dita, esta última falada pelo grupo exógamo patrilinear de mesma designação e atualmente uma espécie de língua franca entre os grupos da região.

${ }^{6}$ Digo idealmente porque, embora a correspondência entre o grupo lingüístico e o grupo exógamo se verifique na maioria dos casos, ela não é universal no Uaupés. Veja-se, por exemplo, o caso dos Tariana (nota 4).

${ }^{7}$ A terminologia de parentesco dos índios do Uaupés é do tipo dravidiano, sendo preferencial o casamento entre primos cruzados bilaterais.

${ }^{8}$ Em 1996, o governo federal declarou de posse permanente dos índios cinco terras contínuas na região do alto e médio Negro, abrangendo $100 \mathrm{mil} \mathrm{km}$. São as seguintes: Terra Indígena Médio Rio Negro I, Terra Indígena Médio Rio 
Negro II, Terra Indígena Rio Téa, Terra Indígena Rio Apapóris, Terra Indígena Alto Rio Negro.

${ }^{9}$ Estas e outras informações estatísticas podem ser encontradas em ISA (2005).

${ }^{10}$ No âmbito do município, além da cidade de São Gabriel, só é possível cursar o Ensino Médio em Iauaretê, povoado localizado no rio Uaupés, que atualmente passa ele próprio por um processo de urbanização e se vê sujeito a pressões demográficas. Para um estudo sobre o cotidiano e a socialidade dos índios residentes em Iauaretê, ver Andrello (2006).

${ }^{11}$ Sobre a questão da violência envolvendo jovens em São Gabriel, ver Lasmar \& Azevedo (2004). Trata-se do relatório de resultados de uma pesquisa participativa realizada no âmbito do Programa de Apoio a Projetos em Saúde, Direitos Sexuais e Direitos Reprodutivos (PROSARE), desenvolvido pela Comissão de Cidadania e Reprodução (CCR) e pelo Centro Brasileiro de Análise e Planejamento (Cebrap).

12 Essas definições foram-me dadas por homens. Quando eu interpelava as mulheres sobre sua pertinência, elas a confirmavam, embora jamais tenham formulado espontaneamente definições parecidas. Sempre me disseram, apenas, que seus filhos eram "morégi".

${ }^{13}$ Para uma análise do enquadramento mitológico da condição específica dos brancos ver Lasmar (2005). 


\section{Referências bibliográficas}

ANDRELLO, Geraldo. 2006. Cidade do índio: transformações e cotidiano em Iauaretê. São Paulo: Edunesp/ ISA/NuTI.

CHERNELA, Janet. 1983. "Estrutura social do Uaupés". Anuário Antropológico, 81:59-69.

- 1993. The Wanano indians of the brazilian Amazon: a sense of space. Austin: University of Texas.

_. 2003. "Language ideology and women's speech: talking community in the Northwest Amazon". American Anthropologist, 105(4):794-806.

DESCOLA, Philippe. 2001. "The genres of gender: local models and global paradigms in the comparison of Amazonia and Melanesia". In: T. Gregor \& D. Tuzin (orgs.), Gender in Amazonia and Melanesia: an exploration of the comparative method. Berkeley: University of California Press. pp. 91-114.

FISHER, William. 2001. "Age-based genders among the Kaiapo". In: T. Gregor \& D. Tuzin (orgs.), Gender in Amazonia and Melanesia: an exploration of the comparative method. Berkeley: University of California Press. pp. 115-141.

GOLDMAN, Irving. 1963. The Cubeo: indians of the Northwest Amazon. Urbana: University of Illinois. - 2004. Cubeo Hehénewa religious thought: metaphysics of a northwestern Amazonian people. New York: Columbia University Press.

HUGH-JONES, Christine. 1977. "Skin and soul: the round and the straight. Social time and social space in Pirá-Paraná society". Actes du XLII Congrès International des Américanistes (Social time and social space in lowland South American societies). Paris: Société des Americanistes. pp. 185-204.

- 1979. From the milk river: spatial and temporal processes in northwest Amazonia. Cambridge: Cambridge University Press.

HUGH-JONES, Stephen. 1977. "Like the leaves on the forest floor...: space and time in Barasana ritual". Actes $d u$ XLII è Congrès International des Américanistes (Social time and social space in lowland South American societies). Paris: Société des Americanistes. pp. 205-215.

- 1979. The palm and the pleiades: initiation and cosmology in northwest Amazonia. Cambridge: Cambridge University Press.

_ 1993. "Clear descent or ambiguous houses? A re-examination of tukanoan social organization". L'Homme, 126-128, XXXIII(2-4):95-120.

. 2002. "Nomes secretos e riqueza visível: nominação no noroeste amazônico". Mana. Estudos de Antropologia Social, 8(2):45-68.

ISA - Instituto Socioambiental. 2005. Caderno de resultados do levantamento socioeconômico e demográfico da cidade de São Gabriel da Cachoeira. São Gabriel: ISA/FOIRN.

JACKSON, Jean. 1983. The fish people: linguistic exogamy and tukanoan identity in northwest Amazonia. Cambridge: Cambridge University Press.

LASMAR, Cristiane. 1998. "Mulheres tukano e urbanização no alto rio Negro". In: H. Buarque de Hollanda \& C. Bruschini (orgs.), Horizontes plurais: novos estudos de gênero no Brasil. São Paulo: Editora 34. pp. 163-191. 
2002. De volta ao lago de leite: a experiência da alteridade em São Gabriel da Cachoeira. Tese de doutorado, PPGAS-MN-UFRJ.

_ 2005. De volta ao lago de leite: gênero e transformação no alto rio Negro. São Paulo: Edunesp/ISA/NuTI.

LASMAR, Cristiane \& AZEVEDO, Marta. 2004. "Violência, sexualidade e relações de gênero em São Gabriel da Cachoeira (AM)". Relatório de pesquisa. PROSARE/CCR e Cebrap. $50 \mathrm{p}$.

LASMAR, Cristiane \& ELOY, Ludivine. 2007. "Urbanização e agricultura indígena no alto rio Negro (AM)". In: Carlos Alberto Ricardo (org.), Povos indígenas no Brasil, 2002-2005. São Paulo: Instituto Socioambiental. pp. 237-242.

MEIRA, Marcio. 1994. "O tempo dos patrões: extrativismo, comerciantes e história indígena no Noroeste da Amazônia". Cadernos Ciências Humanas 2, MCT/CNPq/MPEG.

. 1996. "Conferência: uma nova história do rio Negro". I Simpósio dos Povos Indígenas do rio Negro: Terra e Cultura. Universidade do Amazonas/FOIRN. pp. 121-148.

OLIVEIRA, Ana Gita de. 1995. O mundo transformado: um estudo da cultura de fronteira no alto rio Negro. Belém: Museu Goeldi.

OVERING, Joanna. 1991. "A estética da produção: o senso de comunidade entre os Cubeo e os Piaroa". Revista de Antropologia, 34:7-33.

PIEDADE, Acácio. 1997. A música Ye'pâ Masa: por uma antropologia da música no alto rio Negro. Dissertação de mestrado, Universidade Federal de Santa Catarina.

SANTOS, Antonio Maria de Souza. 1988. Etnia e urbanização no alto rio Negro: São Gabriel da Cachoeira. Dissertação de Mestrado, Instituto de Filosofia e Ciências Humanas, Universidade Federal do Rio Grande do Sul.

WRIGHT, Robin. 1991. "Indian slavery in the northwest Amazon". Boletim do Museu Paraense Emílio Goeldi. Série Antropologia, 7(2):149-179. . 1992. "História indígena do Noroeste amazônico: hipóteses, questões e perspectivas". In: M. Carneiro da Cunha (org.), História dos índios no Brasil. São Paulo: Companhia das Letras. pp. 253-266. 


\section{Resumo}

A posição "deslocada" das mulheres é um traço constitutivo da experiência social feminina no alto rio Negro, em contraste com a masculina, esta fortemente centrada na noção de "pertencimento". Tomando isso por pressuposto, realiza-se, neste artigo, uma reflexão sobre a experiência social das mulheres indígenas que residem na cidade de São Gabriel da Cachoeira, principal pólo urbano da bacia do alto rio Negro. Com base em análise etnográfica, discute-se o modo como os casamentos com brancos na cidade contribuem para o processo de transformação da experiência social feminina.

Palavras-chave Antropologia, Etnologia, Noroeste Amazônico, Gênero, Cidade

\section{Abstract}

The "displaced" position of women is a constitutive feature of female social experience in the Upper Rio Negro, in contrast to the male position which is centred on the notion of "belonging". Starting from this premise, the article reflects on the social experience of Indigenous women who live in the city of São Gabriel da Cachoeira, the principal urban centre in the Upper Rio Negro basin. Through ethnographic analysis, it explores how marriages with white men in the city contribute to the process of transforming female social experience.

Key words Anthropology, Ethnology, Northwest Amazonia, Gender, City 